Tropical Journal of Pharmaceutical Research November 2018; 17 (11): 2207-2211

ISSN: $1596-5996$ (print); 1596-9827 (electronic)

(C) Pharmacotherapy Group, Faculty of Pharmacy, University of Benin, Benin City, 300001 Nigeria.

\title{
Biochemical effects of low-dose whole body $x$-irradiation on mouse liver and the protective action of ectoine
}

\author{
Ghaleb A Oriquat*, Wesam G Ammari \\ Faculty of Pharmacy and Medical Sciences, Al-Ahliyya Amman University, Amman, Jordan \\ ${ }^{*}$ For correspondence: Email: dean_pharm@ammanu.edu.jo; Tel: +962 (0) 795901579
}

Sent for review: 28 October 2018

Revised accepted: 16 October 2018

\begin{abstract}
Purpose: To investigate the possible role of ectoine, which is known to protect protein hydration and folding and structural organization of biological membranes, in protecting mouse liver against low-dose $x$-irradiation.

Methods: The study included thirty Swiss albino mice weighing 20 - $22 \mathrm{~g}$ each, which were divided into five groups of six animals each: group (1) naïve animals serving as control, group (2) animals irradiated with a whole-body 2 Gy single dose of $x$-ray, and sacrificed after one day, group (3) $x$-irradiated and sacrificed after one week (each animal in the 3 groups received $0.2 \mathrm{~mL}$ saline daily by oral gavage). Group 4 consisted of $x$-irradiated animals dosed with ectoine $200 \mathrm{mg} / \mathrm{kg}$ in saline and sacrificed after one day. Group 5 cmoprised of $x$-irradiated animals and were dosed daily with ectoine $200 \mathrm{mg} / \mathrm{kg}$ and sacrificed after one week. The evaluated inflammation parameters in the animals' liver were interleukin$1 \beta$ (IL-1ß), interleukin-6 (IL-6), interleukin-10 (IL-10) and prostaglandin E2 (PGE2). Furthermore, the oxidative stress parameters, viz, malondialdehyde (MDA), reduced glutathione (GSH), oxidized glutathione (GSSG) and their ratio (GSH/GSSG) were also assessed.

Results: Whole body low-dose $x$-irradiation resulted in statistically significant $(p \leq 0.05)$ increases in all ILs tested as well as PGE2 of mice liver. Indications of oxidative stress included elevated levels of MDA and oxidized glutathione with decreased reduced glutathione. The effects of radiation were progressive and the changes in the tested parameters increased from day 1 to day 7. Administration of ectoine significantly $(p \leq 0.05)$ ameliorated the biochemical effects induced by whole body $x$-irradiation. Furthermore, the modulating action was dependent on the accumulation of ectoine, as it was more effective after repeated administration.

Conclusion: Ectoine has a post-irradiation protective effect on mouse liver via its action on inflammatory and oxidative stress pathways. It probably has similar action in other vital organs. Preventive treatment of healthcare personnel and technicians frequently exposed to low doses of radiation with ectoine is worth investigating.
\end{abstract}

Keywords: X-irradiation, Ectoine, Oxidative stress, Mice, Radioprotection

This is an Open Access article that uses a funding model which does not charge readers or their institutions for access and distributed under the terms of the Creative Commons Attribution License (http://creativecommons.org/licenses/by/4.0) and the Budapest Open Access Initiative (http://www.budapestopenaccessinitiative.org/read), which permit unrestricted use, distribution, and reproduction in any medium, provided the original work is properly credited.

Tropical Journal of Pharmaceutical Research is indexed by Science Citation Index (SciSearch), Scopus, International Pharmaceutical Abstract, Chemical Abstracts, Embase, Index Copernicus, EBSCO, African Index Medicus, JournalSeek, Journal Citation Reports/Science Edition, Directory of Open Access Journals (DOAJ), African Journal Online, Bioline International, Open-J-Gate and Pharmacy Abstracts

\section{INTRODUCTION}

Scientific and technological advancements have increased radiation burden in humans, since exposure to low levels of radiation has become common during medical diagnosis procedures, air travel and the use of certain electronic equipment [1]. X-rays are considered indirectly ionizing radiation since their interactions with matter result in liberation of orbital electrons 
which are responsible for the ionization of the target materials or the macromolecular components of biological tissues [2]. Cellular exposure to ionizing radiation can directly disrupt atomic structures, producing chemical and biological changes. It can also act indirectly through radiolysis of water, thereby generating reactive chemical species that may damage nucleic acids, proteins and lipids. Both effects of radiation initiate a series of biochemical and molecular signaling events that may repair the damage or culminate in permanent physiological changes or cell death [3]. Increasing evidence also support the role of chronic oxidative stress in the progression of degenerative diseases and radiation-induced late tissue injury [4].

The compatible solute ectoine, [(s)-2-methyl-1, 4, 5, 6-tetrahydropyrimidine-4-carboxylic acid], is known to preserve and protect both hydration and folding of proteins and the structural organization of membranes [5]. Its protective action against ionizing radiation is worth investigating. The present study was carried out on mice exposed to whole-body $\mathrm{x}$-irradiation using a low dose of 2 Gray (Gy). The changes in inflammatory parameters and those of oxidative stress along with the possible protective effect of ectoine were assessed.

\section{EXPERIMENTAL}

A medical linear accelerator which is a dual photon energy LINAC (Primus, Siemens, Medical System Inc., Concord, CA, USA) was used to generate $\mathrm{x}$-rays [6], with a dose energy rate of 200 cGy / min. Accordingly, irradiation for one minute gives a dose of $2 \mathrm{~Gy}$.

The mice were obtained from the animal house of the Medical Research Institute of Alexandria University, Egypt, and were kept under observation for one week prior to study with feed and water provided ad libitum. The study was approved by the Ethical Committee of the Medical Research Institute at Alexandria University (ref no.: GO/AAU-122012). The experimental procedures were performed according to the international guiding principles of the Institute for Laboratory Animal Research in Guide for the Care and Use of Laboratory Animals [7].

The study included thirty male Swiss albino mice, weighing 20 - $22 \mathrm{~g}$ each, which were divided into five groups of six animals each; group (1) naïve animals serving as controls, group (2) animals irradiated with a whole-body 2 Gy single dose of $x$-ray, and sacrificed after one day, group (3) xirradiated and sacrificed after one week (each animal in the 3 groups received $0.2 \mathrm{~mL}$ saline daily by oral gavage). Group (4) animals were irradiated by a single dose of 2 Gy, then received $200 \mathrm{mg} / \mathrm{kg}$ ectoine in saline [8] orally and were sacrificed after one day. Group (5) Animals were irradiated by a single dose of 2 Gy, received 7 consecutive daily oral doses of $200 \mathrm{mg} / \mathrm{kg}$ ectoine and were sacrificed after one week. At the designated times animals were sacrificed by cervical dislocation. Each sacrificed animal was dissected quickly, and the liver removed, washed with cold saline and stored at $-50{ }^{\circ} \mathrm{C}$ until homogenized and assayed. RayBio ${ }^{\circledR}$ mouse ELISA ready to use kits (RayBiotech, Inc, USA) was used to detect interleukin-1 $\beta$ (IL-1 $\beta$ ), interleukin-6 (IL-6) and interleukin-10 (IL-10) [9].

Prostaglandin E2 (PGE2) was assayed using Gentaur $^{\circledR}$ mouse ELISA kit (Gentaur molecular products, Belgium) [10]. Malondialdehyde (MDA) was assayed by calorimetric reaction [11]. Reduced glutathione (GSH) and oxidized glutathione (GSSG) were assayed by an enzymatic recycling procedure [12].

\section{Statistics}

Statistical analysis was performed using IBM SPSS statistics for Windows, version 20 (Armonk, NY: IBM Corp. 2011). Quantitative data was expressed as mean \pm standard deviation (SD). Differences between means were assessed by one way analysis of variance (ANOVA) followed by Tukey's procedure and were considered statistically significant at $p \leq$ 0.05 .

\section{RESULTS}

As presented in Table 1, irradiation with $\mathrm{x}$-rays resulted in significant elevation of the proinflammatory IL-1 $\beta$ and $1 \mathrm{~L}-6$ as well as the antiinflammatory IL-10. One day after irradiation with 2 Gy the level of IL-1 $\beta$ was $92.8 \%$ above control, which further increased to more than 3 times that of control after 7 days. The results of IL-6 were qualitatively similar to IL-1 $\beta$, with larger changes in the assayed concentrations in response to whole-body $x$-irradiation. One day after irradiation with 2 Gy the mean level of IL-6 was more than 3 times the control value with a substantial increase to a level 10 times above that of control after 7 days.

Results of IL-10 indicated that the level of this anti-inflammatory interleukin increased substantially after the exposure of the animals to $x$-irradiation, which caused significant increases in the IL-10 concentration of $151.8 \%$ after one 
day and $581 \%$ after 7 days compared to the mean control value.

The PGE2 concentration in the mouse liver increased significantly to more than 3 times the control value one day after exposure, which went up to more than 17 times after 7 days.

Treatment with ectoine affected the levels of the 3 tested interleukins (Table 1). When irradiated mice were treated with ectoine the extent of effect was dependent on the duration of drug treatment. A single dose of ectoine resulted in a significant increase in IL-1 $\beta$ of $33 \%$, while daily ectoine administration for 7 days caused a significant decrease of $43.9 \%$.

Similar results were obtained with IL-6. A single dose of ectoine caused an increase in IL-6 in irradiated mice of more than $200 \%$ over the untreated irradiated group. However, seven consecutive daily doses of ectoine caused a significant decrease of $56.0 \%$ below the untreated irradiated group. For IL-10, the results of treatment with ectoine were qualitatively similar to those of IL-6. Compared to the irradiated animals, the level of IL-10 was higher by $73.6 \%$ after one day of ectoine administration, but decreased by $53.8 \%$ after 7 daily doses.

The changes in PGE2 in the livers of mice, as a result of ectoine administration, showed a similar pattern to the results of interleukins. Treatment with a single ectoine dose after one day of irradiation caused an increase in the level of PGE2 of $171 \%$ above that of the untreated irradiated group. However, administration of 7 consecutive daily ectoine doses resulted in a decrease of $50.7 \%$.

The determined parameters of oxidative stress are shown in Table 2. Malondialdehyde; the principal product of lipid peroxidation, is generally used as an indication of oxidative stress. After irradiation by a 2 Gy dose the mean level of MDA increased significantly to 3.8 times that of control. But after seven days the level decreased by 7.3 $\%$ below that after one day, though it was still 3.6 times the control level. X-irradiation decreased the reduced form of glutathione. The 2 Gy dose resulted in a mean decrease of $15.3 \%$ below the control value after one day, but this decrease was only $7.4 \%$ after 7 days.

Oxidative stress was also reflected in the increased oxidation of glutathione. The oxidized form of glutathione (GSSG) doubled one day after irradiation with 2Gy. This increase in the GSSG was halved by day 7 reaching only $48 \%$ above the control.

Treatment with ectoine resulted in significant decreases in MDA levels in all irradiated animals. MDA levels decreased below the respective groups by $12.8 \%$ and $21 \%$ after one day and 7 days. Treatment with ectoine also corrected the decrease in the GSH as its level increased by $12.5 \%$ and $8.3 \%$ after one and 7 days, respectively. The levels of the oxidized glutathione in irradiated mice treated with ectoine decreased by $24 \%$ after one day and by $16.2 \%$ after 7 days, as compared to the corresponding untreated groups.

Table 1: Effect of 2 Gy whole-body x-irradiation and treatment with ectoine on cytokines in mouse liver

\begin{tabular}{lccccc}
\hline Cytokine & \multirow{2}{*}{ Control } & \multicolumn{2}{c}{ 1 day } & \multicolumn{2}{c}{ 7 days } \\
\cline { 3 - 6 } & & Irradiated & Irradiated + Ectoine & Irradiated & $\begin{array}{c}\text { Irradiated + } \\
\text { Ectoine }\end{array}$ \\
\hline $\mathrm{IL}-1 \beta(\mathrm{pg} / \mathrm{g})$ & $18.70 \pm 0.84$ & $36.30 \pm 2.78^{\mathrm{a}}$ & $48.28 . \pm 1.44^{\mathrm{ab}}$ & $58.64 \pm 3.77^{\mathrm{ab}}$ & $32.90 \pm 1.95^{\mathrm{abc}}$ \\
$\mathrm{IL}-6(\mathrm{pg} / \mathrm{g})$ & $8.11 \pm 1.0$ & $25.64 \pm 1.48^{\mathrm{a}}$ & $54.57 \pm 6.39^{\mathrm{ab}}$ & $83.60 \pm 7.37^{\mathrm{ab}}$ & $36.82 \pm 4.39^{\mathrm{abc}}$ \\
$\mathrm{IL}-10(\mathrm{pg} / \mathrm{g})$ & $10.98 \pm 1.0$ & $27.73 \pm 1.88^{\mathrm{a}}$ & $48.13 \pm 3.64^{\mathrm{ab}}$ & $74.98 \pm 5.17^{\mathrm{ab}}$ & $34.63 \pm 3.21^{\mathrm{abc}}$ \\
PGE-2 $(\mathrm{ng} / \mathrm{g})$ & $2.13 \pm 0.25$ & $8.17 \pm 1.19^{\mathrm{a}}$ & $22.14 \pm 2.34^{\mathrm{ab}}$ & $38.04 \pm 2.87^{\mathrm{ab}}$ & $18.76 \pm 3.61^{\mathrm{abc}}$ \\
\hline
\end{tabular}

Table 2: Effect of 2 Gy whole-body x-irradiation and treatment with ectoine on oxidative stress markers in mouse liver

\begin{tabular}{|c|c|c|c|c|c|}
\hline \multirow[b]{2}{*}{ Stress marker } & \multirow[b]{2}{*}{ Control } & \multicolumn{2}{|c|}{1 Day } & \multicolumn{2}{|c|}{7 Days } \\
\hline & & Irradiated & $\begin{array}{c}\text { Irradiated + } \\
\text { ectoine }\end{array}$ & Irradiated & $\begin{array}{c}\text { Irradiated + } \\
\text { ectoine }\end{array}$ \\
\hline MDA $(\mathrm{nmol} / \mathrm{g})$ & $13.2 \pm 2.10$ & $50.8 \pm 5.4^{a}$ & $44.3 \pm 3.6^{\mathrm{ab}}$ & $47.1 \pm 3.6^{\mathrm{a}}$ & $37.2 \pm 4.1^{\mathrm{ab}}$ \\
\hline $\mathrm{GSH}(\mu \mathrm{mol} / \mathrm{g})$ & $4.05 \pm 0.21$ & $3.43 \pm 0.24^{\mathrm{a}}$ & $3.86 \pm 0.17^{a b}$ & $3.75 \pm 0.35^{\mathrm{a}^{*}}$ & $4.06 \pm 0.33^{a b^{*}}$ \\
\hline GSSG $(\mu \mathrm{mol} / \mathrm{g})$ & $0.25 \pm 0.40$ & $0.50 \pm 0.03^{\mathrm{a}}$ & $0.38 \pm 0.04^{\mathrm{ab}}$ & $0.37 \pm 0.04^{\mathrm{a}^{\mathrm{x}}}$ & $0.31 \pm 0.02^{\mathrm{ab}^{\circ}}$ \\
\hline GSH/GSSG ratio & $16.23 \pm 3.12$ & $6.84 \pm 0.28^{a}$ & $10.74 \pm 0.87^{\mathrm{ab}}$ & $10.64 \pm 89^{a_{*}}$. & $13.29 \pm 1.09^{a b^{*}}$ \\
\hline
\end{tabular}

${ }^{\mathrm{a}}$ Significantly different from control; ${ }^{\mathrm{b}}$ significantly different from Irradiated group; *significantly different from 1 day 


\section{DISCUSSION}

The possibility of exposure to low levels of radiation is increasing [1]. This made the threats of late effects of radiation, e.g., reduced fertility, inheritable genetic damage and carcinogenesis assume greater importance. One hypothesis on the potential risk of low-dose radiation proposes that there is no dose of radiation that can be considered completely safe and the use of radiation producing equipment [13] must be based on the risk and benefit. At 2 - 8 Gy radiation syndrome develops with intensity proportional to the radiation dose. This was the basis for the choice of the relatively low radiation dose of 2 Gy used in the present study.

The early biochemical modifications, which occur during or shortly after the radiation exposure, were thought to be responsible for most of the effects of ionizing radiation in mammalian cells [14]. However, oxidative changes may continue to rise after the initial exposure presumably because of continuous generation of reactive oxygen species (ROS) and nitrogen (RNS) species [14].

It has been suggested that the local levels of cytokines reflect the pathological condition in a specific organ and are of a greater value for monitoring pathological events in a target tissue than are systemic serum cytokine levels [15]. In the present study, the $x$-irradiated mice showed elevated interleukins in the livers of all irradiated groups. The increases in IL-1 $\beta$ were accompanied by concomitant increases in IL-6. Interrleukin- $1 \beta$ has been reported to induce IL- 6 [16] which is considered to be an essential contributor to natural resistance to lethal irradiation. Obligatory interaction of IL-1 $1 \beta$ or TNF$\alpha$ with IL-6 may be a prerequisite for some of the biological effects of these inflammatory cytokines.

Induction of IL-6 and/or its receptors has been reported to vary in different tissues and many of the actions of IL-1 $\beta$ can be mimicked by IL- 6 . It is noteworthy that the increases of the proinflammatory cytokines, in the present study, were also accompanied by significant increases in the anti-inflammatory IL-10, which followed the same pattern. Probably such increases represent a defense mechanism against the high levels of $\mathrm{IL}-1 \beta$ and other pro-inflammatory mediators caused by irradiation. It could be postulated that the biological activities of IL-10 in modulating inflammation may be caused, in part, by downregulation of pro-inflammatory cytokines and their receptors, and up-regulation of cytokine inhibitors.
The down-regulation of IL- 6 by IL-10 has been shown [17], and it has been proposed that limiting one step of the inflammatory process cascade might control the progression of the inflammatory reactions. This can be of benefit since it has been shown that the inflammatory reaction is intrinsically destructive for the surrounding tissues [17].

The intracellular increase in the level of IL-1 $\beta$ is followed rapidly by induction of biochemical events including transcription of COX-2 and production of $\mathrm{PGE}_{2}$ [18]. In the present study, $\mathrm{PGE}_{2}$ increased in all groups tested proportional to the time after radiation. A broad spectrum of mediators regulates the expression of COX-2. Whereas, the pro-inflammatory cytokines such as IL-1 $\beta$ and IL- 6 among other factors induce COX-2, the anti-inflammatory e IL-10 inhibits the expression of this enzyme [19]. Therefore, it seems that the balance between the effects of pro-inflammatory and anti-inflammatory cytokines may determine the short-term or long-term outcome of the irradiation effects.

Reduced glutathione, as an antioxidant, has been considered as the most accurate single indicator of cell health, as its depletion represents vulnerability to oxidant attack [20]. The significantly elevated level of reduced glutathione may be a factor responsible for the decrease in the level of MDA generated from lipid peroxidation. In addition, the significant increase in GSH protects cellular proteins against oxidative damage through the glutathione redox cycle and directly detoxifies ROS induced by radiation.

Compatible solutes, including ectoine, are characterized by being effective stabilizers of biomolecules such as proteins, nucleic acids and biological membranes [5]. These properties make them potential candidates for cellular protection. In the present study, treatment with ectoine for one week attenuated the biochemical changes caused by $\mathrm{X}$-irradiation. The seven consecutive doses over one week gave better results than a single dose given one day post irradiation, causing the tested parameters to reach near control levels.

\section{CONCLUSION}

Ectoine has a post-irradiation protective effect on mouse liver as it modulates both the inflammatory and oxidative effects induced by low-dose $x$-irradiation. The modulating action is dependent on the frequency of dosing and accumulation of this compatible solute. It 
probably has a similar action in other vital organs. Preventive treatment of healthcare personnel and technicians frequently exposed to low doses of radiation by ectoine is worth investigating.

\section{DECLARATIONS}

\section{Acknowledgement}

The author is grateful to the staff of the animal house at the Medical Research Institute (MRI) of the Alexandria University, Egypt, for their help during the course of the present work. Thanks are also due to the Administration of the MRI for the facilities they provided. The financial support provided by Al-Ahliyya Amman University, Jordan, is gratefully acknowledged.

\section{Conflict of Interest}

No conflict of interest associated with this work.

\section{Contribution of Authors}

The authors declare that this work was done by the authors named in this article and all liabilities pertaining to claims relating to the content of this article will be borne by them.

\section{REFERENCES}

1. Lushbaugh CC, Casarett GW. The effects of gonadal irradiation in clinical radiation therapy: A review. Cancer 1976; 37(S2): 1111-1120.

2. Grupen C. Astroparticle physics. 1 ed: Springer-Verlag Berlin Heidelberg; 2005; 442.

3. Spitz DR, Azzam El, Li JJ, Gius D. Metabolic oxidation/reduction reactions and cellular responses to ionizing radiation: $A$ unifying concept in stress response biology. Cancer Metastasis Rev 2004; 23(3-4): 311-322.

4. Wickens AP. Ageing and the free radical theory. Respir physiol 2001; 128(3): 379-391.

5. Harishchandra RK, Wulff $S$, Lentzen $G$, Neuhaus $T$, Galla HJ. The effect of compatible solute ectoines on the structural organization of lipid monolayer and bilayer membranes. Biophys Chem 2010; 150(1): 37-46.
6. Coia LR, Moylan DJ. Introduction to clinical radiation oncology: Med Phys Pub 1998.

7. Institute for Laboratory Animal Research: Guide for the Care and Use of Laboratory Animals. Eighth Edition, The National Academies Press, Washington, DC. 2011

8. Abdel-Aziz H, Wadie W, Abdallah DM, Lentzen G, Khayyal MT. Novel effects of ectoine, a bacteria-derived natural tetrahydropyrimidine, in experimental colitis. Phytomedicine 2013; 20(7): 585-591.

9. Burtis CA, Ashwood ER, Bruns DE. Tietz textbook of clinical chemistry and molecular diagnostics. Elsevier saunders 2006; 2448.

10. Burtis CA, Ashwood ER, Bruns DE. Tietz fundamentals of clinical chemistry. Saunders Elsevier 2008.

11. Ohkawa H, Ohishi N, Yagi K. Assay for lipid peroxides in animal tissues by thiobarbituric acid reaction. Anal Biochem 1979; 95(2): 351-358.

12. Griffith OW. Determination of glutathione and glutathione disulfide using glutathione reductase and 2vinylpyridine. Anal Biochem 1980; 106(1): 207-212.

13. Singh VK, Yadav VS. Role of cytokines and growth factors in radioprotection. Exper MI Pathol 2005; 78 : 156-169.

14. Petkau A. Role of superoxide dismutase in modification of radiation injury. Br J Cancer Suppl 1987; 8: 87-95.

15. Mathey E, Pollard J, Armati P. In situ hybridization for cytokines in human tissue biopsies. Cytokine protocols. Humana Press 2004; 41-46.

16. McIntosh J, Jablons D, Mule J, Nordan R, Rudikoff S, Lotze $M$, Rosenberg $S$. In vivo induction of il- 6 by administration of exogenous cytokines and detection of de novo serum levels of il-6 in tumor-bearing mice. $J$ Immunol 1989; 143(1): 162-167.

17. Rubin $P$, Johnston CJ, Williams JP, McDonald $S$, Finkelstein JN. A perpetual cascade of cytokines postirradiation leads to pulmonary fibrosis. Int $J$ Radiat Oncol Biol Phys 1995; 33(1): 99-109.

18. O'Neill LAJ. Towards an understanding of the signal transduction pathways for interleukin 1. Biochimica et Biophysica Acta (BBA) 1995; 1266(1): 31-44.

19. Hinz B, Brune K. Cyclooxygenase-2--10 years later. J Pharmacol Exp Ther 2002; 300(2): 367-375.

20. Bump EA, Brown JM. Role of glutathione in the radiation response of mammalian cells in vitro and in vivo. Pharmacol Ther 1990; 47(1): 117-136. 